\title{
(6) OPEN ACCESS \\ Opening the doors a crack wider: palliative care research data in the public domain
}

\author{
Olav Lindqvist, ${ }^{1,2}$ Birgit H Rasmussen, ${ }^{3,4}$ Carl Johan Fürst, ${ }^{4}$ \\ Carol Tishelman, ${ }^{1,5}$ for the OPCARE9 team in Sweden
}

\begin{abstract}
- Additional material is published online only. To view please visit the journal online (http://dx.doi.org/10.1136/ bmjspcare-2015-000959)

${ }^{1}$ Department of Learning, Informatics, Management and Ethics, Medical Management Centre, Karolinska Institutet, Stockholm, Sweden ${ }^{2}$ Department of Nursing, Umeå University, Umeå, Sweden ${ }^{3}$ Department of Health Sciences, Lund University, Lund, Sweden ${ }^{4}$ The Institute for Palliative Care, Lund University and Skåne Regional Council, Lund, Sweden ${ }^{5}$ Karolinska University Hospital, Innovation Centre, Stockholm, Sweden
\end{abstract}

\section{Correspondence to}

Dr Olav Lindqvist, LIME/Medical Management Centre, Karolinska Institutet, Stockholm SE-171 77 Sweden; olav.lindqvist@ki.se

Received 24 June 2015 Revised 9 November 2015 Accepted 17 December 2015 Published Online First 18 January 2016

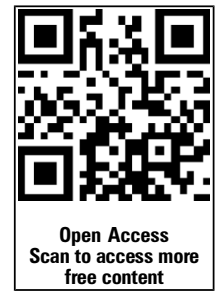

\section{CrossMark}

To cite: Lindqvist $\mathrm{O}$, Rasmussen BH, Fürst CJ, et al. BMJ Supportive \& Palliative Care 2016;6:113-115.

\section{ABSTRACT}

This report builds further on OPCARE9, an EU

7th framework project aiming to identify

knowledge gaps in care provision in the last days

of life. This study began with curiosity about new ways of generating research questions to meet future challenges in palliative care (PC) and how to better engage disciplines not generally included in PC research. We here describe an innovative methodological approach to generating data; put data relevant for PC research in the public domain; and raise issues about open access in PC research. We aimed to compile research questions from different disciplines, based on raw data consisting of approximately 1000 descriptions of nonpharmacological caregiving activities (NPCAs), generated through previous research. 53 researchers from different fields were sent the full list of NPCAs and asked to generate research questions from their disciplinary perspective. Responses were received from 32 researchers from 9 countries, generating approximately 170 research topics, questions, reflections and ideas, from a wide variety of perspectives, which are presented here. Through these data, issues related to death and dying are addressed in several ways, in line with a new public health approach. By engaging a broader group of disciplines and facilitating availability of data in the public domain, we hope to stimulate more open dialogue about a wider variety of issues related to death and dying. We also introduce an innovative methodological approach to data generation, which resulted in a response rate at least equivalent to that in our Delphi survey of professionals in OPCARE9.

\section{BACKGROUND AND AIMS}

According to Tinetti, ${ }^{1}$ death might be considered the most common of all 'health events'. However, death is far more than a health event; it is an expected and unavoidable part of life, inextricably interwoven with different underlying cultural norms. Death, dying and bereavement are also extraordinary, memorable and often difficult experiences for individuals and their families. Experiences related to end-of-life (EoL) care are thus major public health issues as everyone is affected by the deaths of others close to them as well as by their own mortality.

Palliative care (PC) has traditionally been defined by Cicely Saunders as intrinsically multidimensional in its attention to 'total pain', ${ }^{2}$ that is, suffering and distress encompassing all forms of a person's struggles when approaching death. Despite increasing recognition of and appreciation for the importance of non-pharmacological care, this multidisciplinary and transdisciplinary openness is not always fully represented in much PC research, which remains dominated by health professionals with pharmacological and specialist interventions and perspectives often highlighted. Even when addressing social, spiritual and practical issues, perspectives representing PC professional specialty services are often central.

Perspectives stemming from 'new public health' provide alternatives to this professional, specialty-based focus. ${ }^{3} \mathrm{New}$ public health, ${ }^{4}$ inspired in part by the WHO's Ottawa Charter for Health Promotion from $1986,{ }^{5}$ explicitly involves communities in health promotion by enabling them to increase control over care through capacity building and empowerment. This community-based health promotion framework was initially applied to PC contexts by Kellehear and Sallnow. ${ }^{4}$ Our present work with 'healthpromoting PC' has led us to increasingly recognise a need to re-conceptualise how 
we conduct PC research if we are to begin to meet the challenges we are facing for the future. The need for new types of partnerships with various communities, including representatives of disciplines which have hitherto rarely been included in PC research, becomes clear when facing 'wicked problems', that is problems not readily fixed with discrete solutions, due to their changing, contradictory requirements and complex interdependencies. ${ }^{6}$ We also note that the trend towards open access, both in terms of publication of research results and in open access to databases, has had limited traction in much PC research to date. This professional protectionism may be understood to some extent as a function of our history, and the need to establish a position in the curatively oriented healthcare field; however, it may be time to reconsider different means of meeting the future of scholarship and care proactively.

The aims of this short report are therefore to make efforts in this direction by:

1. Describing an innovative methodological approach to generating data;

2. Putting data of potential relevance for PC research in the public domain;

3. Raising issues about how open access to knowledge might impact a PC paradigm and research.

\section{METHODS}

The data presented here derive from a follow-up study to a prior publication ${ }^{7}$ based on research conducted within OPCARE9, an EU 7th framework project aiming to identify knowledge gaps necessary to fill in order to optimise palliative cancer care provision in the last days of life. Systematic literature reviews and Delphi panels were generally employed as methods for this. Within an OPCARE9 work package on alleviating distress through pharmacological and non-pharmacological means, we instead used a variation of freelisting, ${ }^{8-10}$ an approach with roots in anthropology, to elicit descriptions of nonpharmacological caregiving activities (NPCAs) performed in specialised PC facilities in the nine OPCARE9 countries.

After Swedish pilot testing, a representative from each OPCARE9 country was asked to perform a brainstorming activity with at least one PC unit in his/ her country, discussing which interventions and activities-besides administering medications-staff carried out with patients and families during the last days and hours of life. A first list of activities was generated, using spoken language, with descriptions in as much detail as possible. Staff was requested to add activities to the lists for 3-4 more weeks. 7

The published results were based on inductive analysis of the variation found in the 914 statements about NPCAs generated from 16 specialised PC facilities in OPCARE9 countries in this manner. Given the nature of the generated NPCA data, with activities often integrated and carried out simultaneously, prioritisation and ranking fundamental to a Delphi study were not judged meaningful. In a second phase, we instead made efforts to identify knowledge gaps by data sharing with a variety of experts to generate new research questions related to non-pharmacological care provision, in a manner we have not seen documented in the literature.

We contacted 53 senior researchers internationally active in different fields. The aim of this qualitative approach was to generate and compile research questions from different disciplinary perspectives, using the generated list of NPCAs as a basis for this. We sent out lists of the full data set of NPCAs, alphabetised by the first letter in the description of the activity. We requested that the researchers briefly browse the lists and formulate three research questions that quickly come to mind from their disciplinary perspective. All researchers were sent the same data, but the lists were sorted differently with regard to the letter beginning the alphabetised list. This was done to assure variety if researchers only examined the first few pages of the list.

\section{ETHICAL CONSIDERATIONS}

In all studies conducted through OPCARE9, ethical principles for research were followed in accordance with norms in each of the nine involved countries; whether formal ethical review was necessary or not varied by country. All staff contributing NPCA data were aware of the purpose of the study and agreed to contribute. The data collection via researchers was not necessary to subject to ethical review in Sweden, as the research issue was not sensitive, no personal information was provided, and the subjects were not in a dependent situation. However, all recipients of the invitation to participate were informed from the onset that the data generated would be published to provide a resource for all interested parties, and that publication would take place in a manner that prohibited a link to the individual respondent.

\section{RESULTS}

Responses were received from 32 researchers from nine countries, not identical with the OPCARE9 countries, who together generated approximately 170 research topics, questions, reflections and ideas. The respondents replied from the perspectives of palliative practitioners and researchers in behavioural science, medicine, nursing, occupational therapy and social work. Those without backgrounds in PC have expertise in anthropology, art, complementary and alternative therapies, ethics, IT sciences, medical history; yet others had backgrounds from social sciences and other healthcare fields. All the topics generated pertain to areas of potential interest for further research to benefit PC; these data are presented verbatim in online supplementary appendix 1. 


\section{DISCUSSION}

Through this short report, we act on our commitment to address neglected issues related to death and dying as phenomena from both healthcare and nonhealthcare perspectives in line with a new public health approach in several ways. By engaging a broader group of disciplines and facilitating availability of data in the public domain, we hope to stimulate more open dialogue about a wider variety of issues related to death and dying in a range of forums beyond those generally included in PC. We have also briefly described an innovative methodological approach to data generation, which resulted in a response rate at least equivalent to that achieved in our more traditional Delphi survey of professionals in OPCARE9. ${ }^{11}$ The data presented here are, however, limited in that we make no claims as to which, if any, of the issues raised in the generated data have been addressed in prior research; nor have we evaluated the quality of the responses in any manner here. We fulfil our ambitions to stimulate variety in new research areas to fill knowledge gaps, rather than prioritisation as would have been the case had we used a Delphi panel.

Finally, we believe that inclusion of a broader range of professional and community competencies has much to offer PC for the future, in terms of improving care, improving research and incorporating knowledge exchange as a form for research dissemination. As open access to information increasingly gains credibility, we need to expand the types of impact we hope PC research may make. The home page of 'The open access week' claims: "Open access...has the power to transform the way research and scientific inquiry are conducted. It has direct and widespread implications for academia, medicine, science, industry, and for society as a whole." 12 As the Open Society also points out, open access "supports the unfettering of knowledge created through academic research both as an essential public good and as a way to address the gap between the production of academic knowledge and the needs of civil society." 13 These goals are essential in our joint efforts to improve palliative and end-of-life care for broad populations.

Acknowledgements The authors would like to thank the international experts who participated in this study. They would also like to thank the country representatives in the OPCARE9 countries for their assistance in different phases of the project: Jean B Clark (New Zealand), Maria L Daud (Argentina), Andrew Dickman (UK), Franzisca Domeisen Benedetti (Switzerland), Maren Galushko (Germany), Urska Lunder (Slovenia), Guido Miccinesi (Italy) and Lia van Zuylen (the Netherlands).

Collaborators The OPCARE9 team members in Sweden are: Carl-Johan Fürst (PI), Carina Lundh Hagelin, Olav Lindqvist, Gunilla Lundquist, Birgit H Rasmussen, Sylvia Sauter and Carol Tishelman.
Contributors All authors have contributed equally to the study design and data collection. OL and CT have contributed equally to drafting the manuscript which has been approved by all authors.

Funding Data collection for this project was conducted as part of the OPCARE9 project, funded by the European Commission's Seventh Framework Programme (contract number HEALTH-F2-2008-202112). Additional funding has been received from Forte: Swedish Research Council for Health, Working Life and Welfare (2013-1962; 2014-4071).

\section{Competing interests None declared.}

Provenance and peer review Not commissioned; externally peer reviewed.

Open Access This is an Open Access article distributed in accordance with the Creative Commons Attribution Non Commercial (CC BY-NC 4.0) license, which permits others to distribute, remix, adapt, build upon this work noncommercially, and license their derivative works on different terms, provided the original work is properly cited and the use is non-commercial. See: http://creativecommons.org/licenses/by$\mathrm{nc} / 4.0 /$

\section{REFERENCES}

1 Tinetti ME. The retreat from advanced care planning. JAMA 2012;307:915-16.

2 Clark D. 'Total pain', disciplinary power and the body in the work of Cicely Saunders, 1958-1967. Soc Sci Med 1999;49:727-36.

3 Sallnow L, Tishelman C, Lindqvist O, et al. Research in public health and end of life care-Building on the past and developing the new. Prog Palliat Care. [In press].

4 Kellehear A, Sallnow L. Public health and palliative care: an historical overview. In: Sallnow L, Kumar S, Kellehear A, eds. International perspectives on public health and palliative care. New York: Routledge, 2012:1-12.

5 World Health Organization: The Ottawa Charter for Health Promotion. http://www.who.int/healthpromotion/conferences/ previous/ottawa/en/ (Last accessed 9 Nov 2015).

6 Periyakoil VS. Taming wicked problems in modern health care systems. J Palliat Med 2007;10:658-9.

7 Lindqvist O, Tishelman C, Hagelin CL, et al. Complexity in non-pharmacological caregiving activities at the end of life: an international qualitative study. PLoS Med 2012;9:e1001173.

8 Bernard HR. Research methods in anthropology. Qualitative and quantitative approaches. 3rd edn. New York: Altamira Press, 2002.

9 Tishelman C, Lövgren M, Broberger E, et al. Are the most distressing concerns of patients with inoperable lung cancer adequately assessed? A mixed-methods analysis. J Clin Oncol 2010;28:1942-9.

10 Weller SC, Romney AK. Systematic data collection. Newbury Park, CA: Sage Publication, 1988.

11 Lindqvist O, Lundquist G, Dickman A, et al. Four essential drugs needed for quality care of the dying: a Delphi-study based international expert consensus opinion. J Palliat Med 2013;16:38-43.

12 Open Access Week: About. http://www.openaccessweek.org/ page/about (Last accessed 9 Nov 2015).

13 Open Society Foundations: Open Access Initiative. http://www. opensocietyfoundations.org/grants/open-access-initiative (Last accessed 9 Nov 2015). 